\title{
Facial reanimation with masseter nerve-innervated free gracilis muscle transfer in established facial palsy patients
}

\author{
Tae Suk Oh, Hyung Bae Kim, Jong Woo Choi, Woo Shik Jeong \\ Department of Plastic Surgery, Asan Medical Center, University of Ulsan College of Medicine, Seoul, Korea
}

Background The masseter nerve is a useful donor nerve for reconstruction in patients with established facial palsy, with numerous advantages including low morbidity, a strong motor impulse, high reliability, and fast reinnervation. In this study, we assessed the results of masseter nerve-innervated free gracilis muscle transfer in established facial palsy patients.

Methods Ten patients with facial palsy who received treatment from January 2015 to January 2017 were enrolled in this study. Three patients received masseter nerve-only free gracilis transfer, and seven received double-innervated free gracilis transfer (masseter nerve and a cross-face nerve graft). Patients were evaluated using the Facial Assessment by Computer Evaluation software (FACEgram) to quantify oral commissure excursion and symmetry at rest and when smiling after muscle transfer.

Results The mean time between surgery and initial movement was roughly 167.7 days. A statistically significant increase in excursion at rest and when smiling was seen after muscle transfer. There was a significant increase in the distance of oral commissure excursion at rest and when smiling. A statistically significant increase was observed in symmetry when smiling. Terzis' functional and aesthetic grading scores showed significant improvements postoperatively.

Conclusions Masseter nerve innervation is a good option with many uses in in established facial palsy patients. For some conditions, it is the first-line treatment. Free gracilis muscle transfer using the masseter nerve has excellent results with good symmetry and an effective degree of recovery.

Keywords Facial nerve / Free tissue flap / Facial paralysis
Correspondence: Tae Suk Oh Department of Plastic Surgery, Asan Medical Center, University of Ulsan College of Medicine, 88 Olympic-ro 43-gil, Songpa-gu, Seoul 05505, Korea

Tel: +82-2-3010-3600

Fax: +82-2-476-7471

E-mail: tasuko@amc.seoul.kr

Received: 17 Jun 2018 • Revised: 28 Oct 2018 • Accepted: 7 Feb 2019

pISSN: 2234-6163 • elSSN: 2234-6171 • https://doi.org/10.5999/aps.2018.00717• Arch Plast Surg 2019;46:122-128

\section{INTRODUCTION}

Numerous treatment options exist for facial paralysis. Most importantly, the length of time over which the disease has developed should be considered to identify the best possible option.
Especially for patients with longstanding established facial palsy, free functional muscle transfer is known as the gold-standard treatment. A critical aspect of this surgical procedure is the selection of a motor nerve for innervation of the transferred muscle. The contralateral facial nerve, used by means of a cross-face 
nerve graft, is traditionally considered the first choice as a nerve source $[1,2]$. Surgeons can create a spontaneous and synchronous smile with a cross-face nerve graft using the contralateral facial nerve (cranial nerve [CN] VII). However, the presence of two nerve coaptations leads to certain drawbacks, such as low predictability and consistency of muscle contraction [3]. Furthermore, this technique involves 2-stage surgery, and patients must wait for several months after the first stage for the procedure to be completed.

Contrastingly, functional gracilis muscle transfer (FGMT) using the masseter nerve is now gaining popularity. The masseter nerve has a greater axonal load than cross-face nerve grafts, resulting in stronger motor innervation [4]. Furthermore, it causes less axonal loss than cross-face nerve grafts because one fewer nerve coaptation is required [5]. FGMT can be a good alternative if the contralateral facial nerve is damaged or inappropriate for use, especially because it is done in a single stage.

This study aimed to analyze the effectiveness and outcomes of single-stage free gracilis muscle transfer using the masseter nerve as the main neurotizer. An analysis was carried out to explore whether FGMT using the masseter nerve was able to provide appropriate motor power and whether it improved facial function and symmetry.

\section{METHODS}

A retrospective analysis was performed of patients who received

\section{Fig. 1. Photo analysis of a patient}

Note that the oral commissure excursion is the measurement from the midline of the lower lip to the oral commissure (A-line). Symmetry was measured according to the ratio between the A-line and B-line (the contralateral side of the paralyzed face). FACEgram, Facial Assessment by Computer Evaluation software.

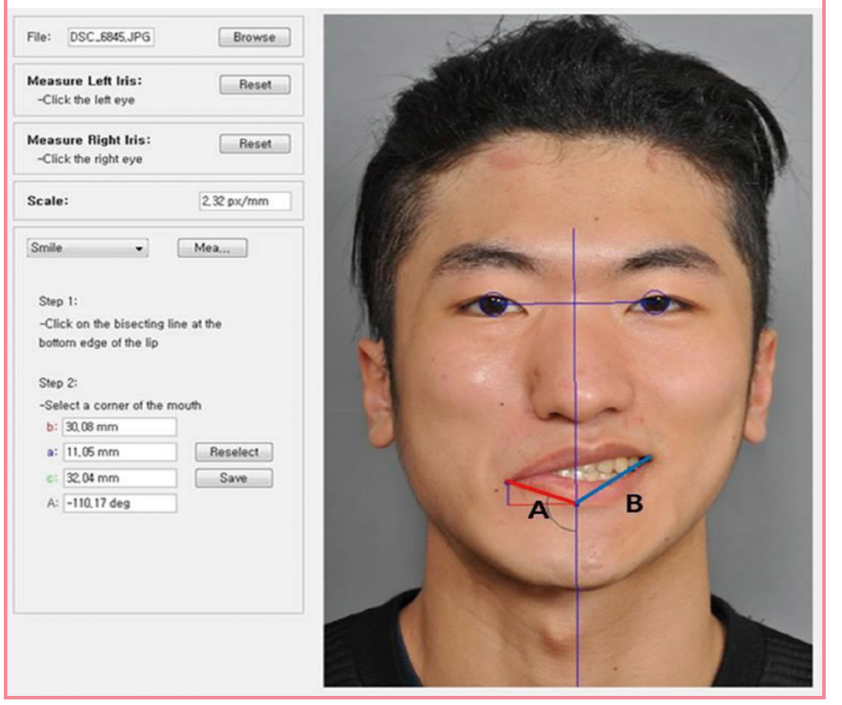

treatment from January 2015 to January 2017. Ten patients who underwent FGMT using the masseter nerve as the main nerve source were enrolled in this study. The demographic characteristics of all patients were evaluated, as well as the causes of facial paralysis, the time interval between surgical stages and initial movement, and disease period. Preoperative and postoperative photographs were analyzed using the Facial Assessment by Computer Evaluation software (FACEgram), a software program used to calculate the smile excursion (the distance from the midline of the lower lip to the oral commissure) and the angle of oral commissure elevation on the affected and unaffected side (Fig. 1). The ratio of the excursion distances on both sides was calculated and used to evaluate facial symmetry. The preoperative and postoperative videos and photographs of each patient were reviewed by an investigator using Terzis' functional and aesthetic grading scale (Table 1 ).

Double-innervated gracilis muscle transfer was indicated for complete facial palsy patients who wanted a natural smile with good excursion. The indications of masseter nerve-only innervated gracilis muscle transfer were old age, desire for a less invasive procedure, significant comorbidities, and unavailability of the contralateral facial nerve.

\section{Surgical techniques}

A facelift-type incision was made on the paralyzed face. A skin flap was elevated above the deep subcutaneous tissue and dissected around the nasolabial fold through the sub-superficial muscular aponeurotic system (SMAS) plane. The masseter nerve was found in the muscle parenchyma. We used the subzygomatic triangle introduced by Collar et al. [6] to find the masseter nerve. This triangle is formed by the inferior border of the zygomatic arch superiorly, a vertical line through the anterior border of the temporomandibular joint posteriorly, and the frontal branch of the facial nerve inferiorly and anteriorly. The average time to find the masseter nerve was 15 minutes. The depth of the masseter nerve was roughly 1 to $2 \mathrm{~cm}$. A nerve stimulator was used to find the correct nerve.

A gracilis muscle flap, measuring $10 \times 5 \mathrm{~cm}$ on average, was harvested at the medial thigh in the standard manner. The graci-

Table 1. Terzis' functional and aesthetic grading system

\begin{tabular}{|lll|}
\hline Grade & \multicolumn{1}{c|}{ Description } & Result \\
\hline 1 & Deformity, no contraction & Poor \\
2 & No symmetry, minimal contraction & Fair \\
3 & Moderate symmetry and contraction & Moderate \\
4 & Symmetry, nearly full contraction & Good \\
5 & Symmetrical smile with full contraction & Excellent \\
\hline
\end{tabular}


lis muscle was dissected, and the flap vessels and obturator nerve were dissected with sufficient pedicle length. The gracilis muscle was cut using a GIA device-reloadable linear cutter with a safety lock-out device (Ethicon Endo-surgery, LLC, Dülmen, Germany). Vascular anastomosis was performed in the usual manner. The donor vessels were all facial vessels. End-to-end neurorrhaphy of the masseter nerve and obturator nerve was performed under microscopy.

Seven patients underwent a double-innervation procedure using a cross-face nerve graft. On the healthy side of the face, an incision was made on the cheek and the buccal branch of the facial nerve was found using a nerve stimulator. Using the nerve stimulator, we checked the movement of the zygomatic major muscle. At the same time, the second team harvested the sural nerve. The mean diameter of the sural nerve graft was $18 \mathrm{~cm}$. The sural nerve graft was coapted with the buccal branch of the facial nerve in an end-to-end manner and was also coapted with the masseter nerve in an end-to-side manner (Fig. 2).

Finally, the gracilis muscle was fixed at the periosteum of the lateral zygomatic bond and the medial side of the nasolabial fold. A nasolabial incision was performed in elderly patients and patients with severe nasolabial disruption. De-epithelialization of the nasolabial fold skin and anchoring sutures to the base of the nasolabial fold were performed for nasolabial fold formation. In cases of relatively young patients who did not want scar formation, we made a transverse incision on the lip for muscle fixation. The proximal gracilis muscle was sutured to the periosteum or the SMAS layer with 3-0 absorbable sutures near the zygomatic arch, and the distal gracilis muscle was sutured to the modiolus, upper lip, and lower lip with 3-0 absorbable sutures.

All patients were given instructions to use an external electrical muscle stimulator to rehabilitate the transferred muscle starting 2 weeks after surgery, and patients were also educated about the use of biofeedback with a mirror to obtain a spontaneous and natural smile.

\section{Data analysis}

Statistical analysis was performed using SPSS version 21.0 (IBM Corp., Armonk, NY, USA). The paired two-tailed t-test was

\section{Table 2. Patients' demographic and clinical data}

\begin{tabular}{|lc|}
\hline & \multicolumn{1}{c|}{ Masseter nerve-innervated FGMT } \\
\hline Age (yr) & 46.6 \\
No. of patients (male:female) & $10(3: 7)$ \\
Follow-up time (mon) & $15.00(6.5-23.16)$ \\
Facial palsy onset to FGMT (yr) & $20.7(2-60)$ \\
\hline Value are presented as mean or average (range). & \\
FGMT, functional gracilis muscle transfer. & \\
\hline
\end{tabular}

used to compare preoperative and postoperative smile excursion distances and angles on the affected and unaffected sides. The symmetry score was calculated as the ratio between the affected and unaffected sides, and the preoperative and postoperative scores at rest and when smiling were compared using the paired two-tailed t-test. Differences between Terzis' grading scores were evaluated with the Mann-Whitney test.

\section{RESULTS}

Ten patients treated at Asan Medical Center between January 2015 to January 2017 were evaluated. Three patients received free FGMT with only the masseter nerve, while seven patients received double-innervation FGMT. Patients' demographic and clinical data are presented in Table 2 . The average time between facial palsy onset and FGMT was 20.7 years (range, 2-60 years). The average time of initial muscle movement after surgery was 167.7 days (range, $83-360$ days).

Fig. 3 summarizes the pathophysiology of facial palsy in our patients. Tumor resection was the most frequent cause of facial palsy (5/10).

Terzis' functional and aesthetic grading scores were evaluated

\section{Fig. 2. Scheme of surgery}

Single-stage surgery with double-innervated free functional muscle transfer innervated by the masseter nerve (end-to-end anastomosis) and the cross-face nerve graft (end-to-side anastomosis).

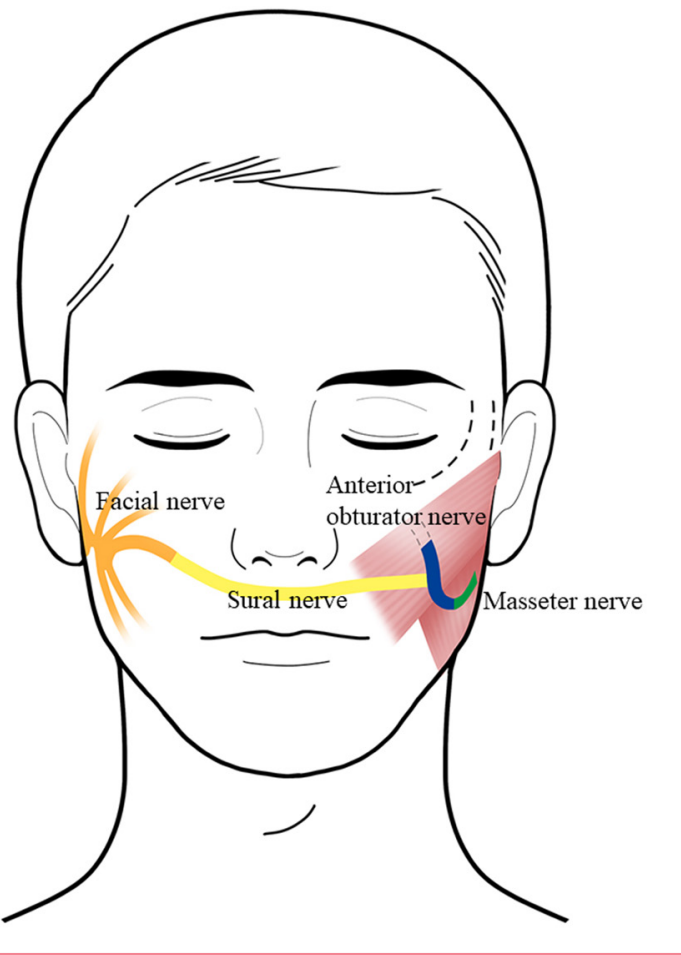


Fig. 3. Pathophysiology of facial palsy in our patients

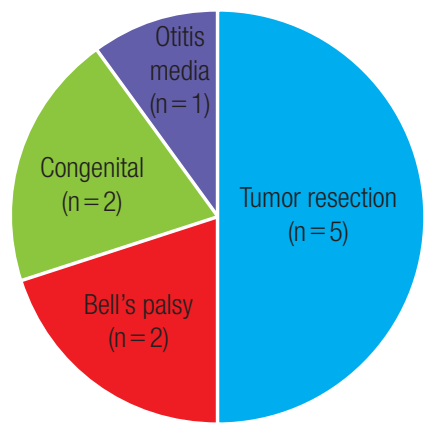

preoperatively and postoperatively. In both groups, there were significant changes between the preoperative and postoperative grading scores (paired two-tailed t-test, $\mathrm{P}=0.02$ ) (Table 3).

Using FACEgram, we evaluated the oral commissure position, the oral commissure excursion, and symmetry at rest and when smiling. In the patients who received a cross-face nerve graft, a significant increase was observed in oral commissure excursion at rest and when smiling (paired two-tailed $t$ test, $\mathrm{P}=0.02$ at rest and $\mathrm{P}=0.005$ when smiling). Symmetry was calculated as the ratio of the oral commissure excursion on the affected side to that on the unaffected side. Significant improvement was found in symmetry when smiling (paired two-tailed t-test, $\mathrm{P}=0.003$ ). However, no statistically significant difference was found in the degree of symmetry at rest (Table 3 ).

\section{DISCUSSION}

The most important aspect of facial reanimation surgery is to choose the most appropriate surgical option. Numerous surgical techniques have been developed, and still others are being innovated $[7,8]$. Conventionally, FGMT using a cross-face nerve graft is the gold-standard treatment [1]. FGMT using a cross-face nerve graft consists of a 2 -stage procedure with primary cross-face nerve graft surgery and subsequent free muscle transfer surgery that is performed 6 to 12 months later. FGMT using a cross-face nerve graft can create a spontaneous and natural smile because the transferred muscle is innervated by the contralateral facial nerve (CN VII). Despite its advantages, it also has multiple drawbacks. First, the length of the nerve can be an obstacle to nerve regeneration. Another shortcoming is axonal loss due to the presence of two anastomosis sites. This can result in a long denervation time, which can cause muscle atrophy or sometimes even a catastrophic result, such as immobility of the muscle flap [3].

FGMT using the masseter nerve has recently become more
Table 3. Outcome assessments

\begin{tabular}{|lccc|}
\hline & $\begin{array}{c}\text { Preoperative } \\
\text { value }\end{array}$ & $\begin{array}{c}\text { Postoperative } \\
\text { value }\end{array}$ & P-value \\
\hline Excursion distance (mm) & & & \\
$\quad$ At rest & 23.94 & 28.55 & 0.029 \\
$\quad$ When smiling & 22.02 & 31.60 & 0.010 \\
Symmetry index (0-1) & & & \\
$\quad$ At rest & 0.80 & 0.85 & 0.340 \\
$\quad$ When smiling & 0.62 & 0.84 & 0.001 \\
Terzis' functional and aesthetic & 1.30 & 2.50 & 0.000 \\
grade (1-5) & & & \\
\hline $\begin{array}{l}\text { Values are presented as mean. } \\
\text { a'Grade 1 (poor) to 5 (excellent). }\end{array}$ & & & \\
\hline
\end{tabular}

popular as a technique that can achieve relatively consistent and strong muscle contractions because it uses the strong axonal load of the masseter nerve $[4,5,9]$. According to a study using electron microscopy, the average axonal count of the masseter nerve is 1,542 , compared to 834 for the facial nerve and a reported number of 100 to 200 for the distal end of cross-facial nerve grafts [5]. Furthermore, FGMT using the masseter nerve requires a single nerve coaptation, and less axonal loss occurs due to the relatively short length of the nerve. In this study, FGMT using the masseter nerve showed satisfactory results in terms of excursion, leading to improvements in symmetry (Fig. 4).

Double innervation was introduced by Biglioli et al. [8]. The advantage of double innervation is that it guarantees strong nerve input by the masseteric nerve, allowing motor innervation to be maintained even if the cross-face nerve graft fails. Furthermore, nerve innervation from a cross-face nerve graft has the potential to enable a spontaneous smile through neural supercharge (Fig. 5) $[8,10]$.

In FGMT with double innervation, controversy exists regarding which nerve is the main neurotizer of the transferred muscle and the timing of reinnervation of the two nerves. Biglioli et al. [8] recorded motor potentials during electrical stimulation of the contralateral facial nerve by using a coaxial needle inserted into the transferred muscle in patients who received double-innervated FGMT, and observed the excitability of the grafted facial nerve fibers. However, they reported that they failed to check the masseter muscle because of artifacts. Further studies with electromyography, nerve conduction velocity evaluation, or functional magnetic resonance imaging will be needed to identify which nerve is the main neurotizer. There was a clinically observable reduction of excursion with mastication at the time when innervation of the cross-face nerve graft was transmitted to the muscle in patients with double-innervated FGMT. This might be another phenomenon explained by cerebral adaptation theory, and it is likely that the smile center of the cere- 


\section{Fig. 4. A case of masseter nerve-innervated FGMT}

A 48-year-old woman presented with complete left-sided facial paralysis after resection of hemangioma. The denervation time was 45 years. She received masseter nerve-innervated free functional muscle transfer (FGMT). (A) Preoperative appearance of the patient at rest. (B) Preoperative appearance when smiling. (C) Postoperative appearance at rest. (D) Postoperative appearance when smiling.
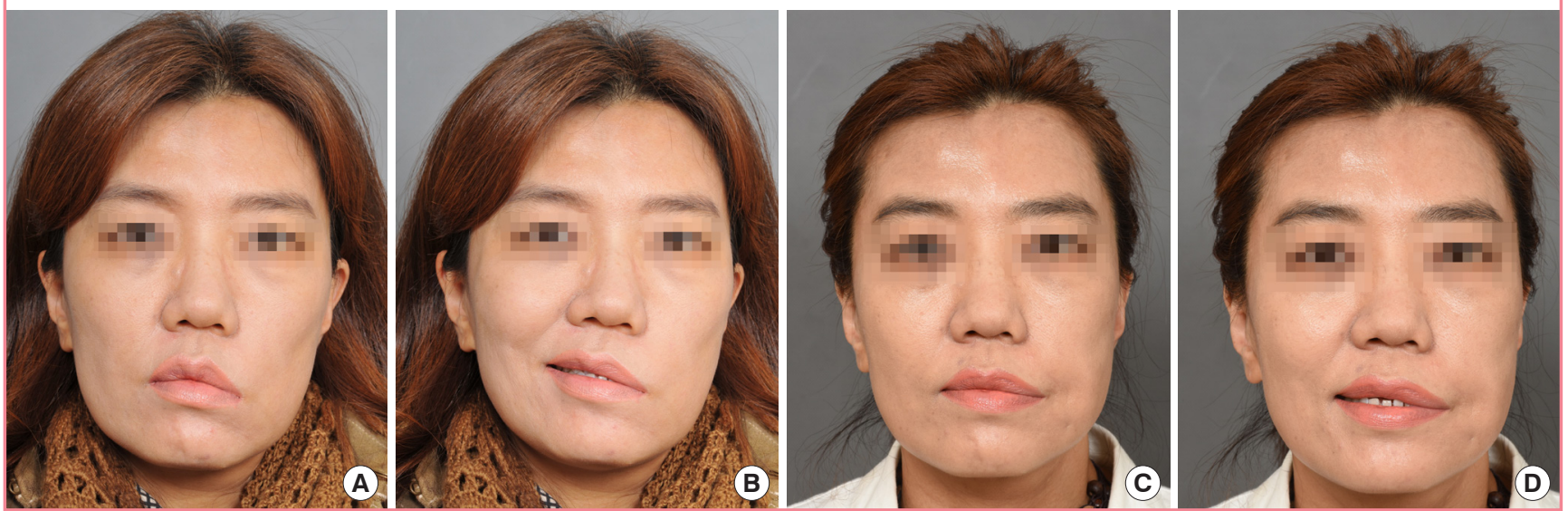

\section{Fig. 5. A case of double-innervated FGMT}

A 57-year-old woman presented with incomplete left-sided facial paralysis after extirpation of a vestibular schwannoma. The denervation time was 19 years. She received double-innervated free functional muscle transfer (FGMT). (A) Preoperative appearance of the patient at rest. (B) Preoperative appearance when smiling. (C) Postoperative appearance at rest. (D) Postoperative appearance when smiling.
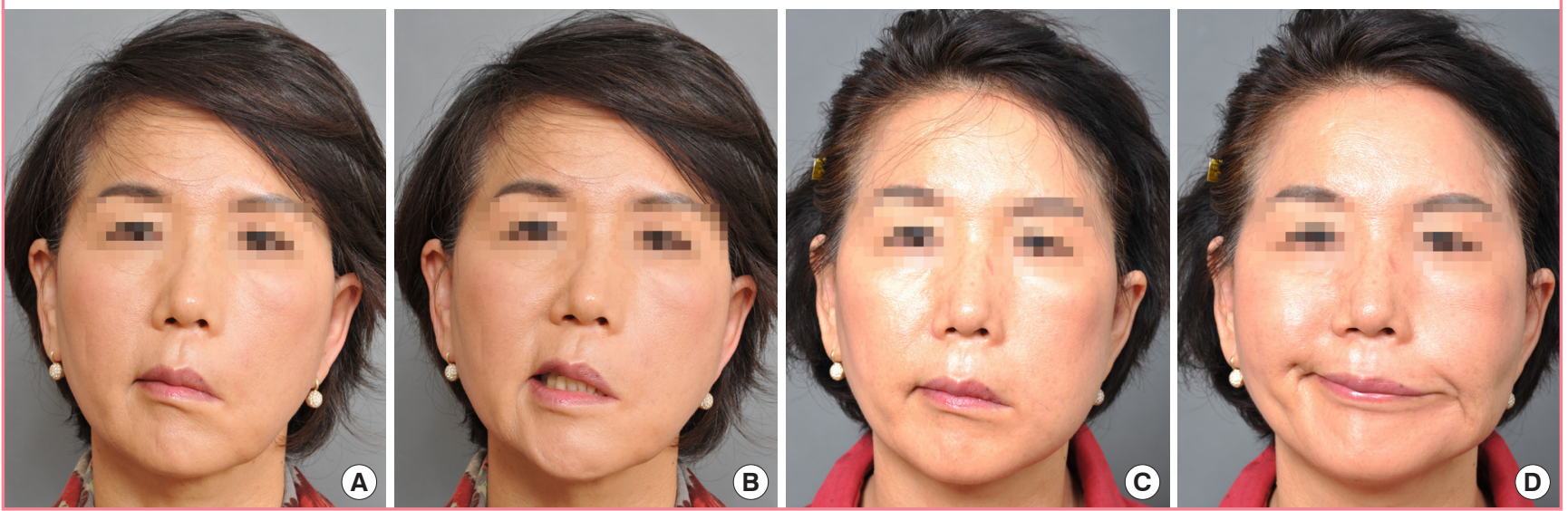

bral cortex shifts from the facial movement center to the jaw muscle center.

Using the masseter nerve as the main neurotizer has certain drawbacks. The masseter nerve is innervated by $\mathrm{CN}$ V and requires a primary masticatory action to make a smile, which can be an obstacle to spontaneous smiles, unlike what occurs when a cross-face nerve graft is used. However according to a study by Manktelow et al. [11], spontaneous smiles occurred in 59\% of patients who underwent muscle transfer using the masseter nerve after repeated practice and training. They explained this result through the concept of cerebral adaptation, according to which repeated practice induces neural connections between the CN V cortical center and the CN VII cortical center in the cerebral cortex, thereby resulting in a natural smile without mas- ticatory action. Lifchez et al. [12] also reported that two of three patients with Möbius syndrome who underwent free muscle transfer using the masseter nerve achieved the ability to smile independently of jaw closure. Bae et al. [9] evaluated 166 free gracilis muscle flaps in children with facial palsy to compare outcomes between cross-face nerve grafts and grafting the motor nerve to the masseter nerve. They concluded that using the masseter nerve as the nerve source led to better excursion than the cross-face nerve grafts.

The choice of whether to make an incision on the nasolabial fold or vermilion is also an important factor to consider in muscle fixation. In this study, the muscle was fixed to the modiolus using a facelift-type incision without an additional incision on the nasolabial fold or vermilion. When the modiolus could not 
be reached using a hand tie, a tie was made using a note-pusher. However, smile excursion occurred in unwanted sites in some cases. In these cases, an incision was made on the nasolabial fold to redo muscle fixation, and nasolabial fold formation was performed by de-epithelialization of part of the skin. Since nasolabial fold scars are relatively favorable, rigidly fixing the muscle by making an incision on the nasolabial fold in the initial surgical procedure can also be a favorable option.

Another possible problem is muscle atrophy, which can be caused by the absence of nerve stimulation during the re-innervation period following muscle transfer. Masseter nerve innervation might bring about relatively rapid nerve regeneration compared to cross-face nerve grafts, thereby reducing the incidence of muscle atrophy. We also made use of an external muscle stimulator to prevent such incidents. All patients were instructed to use an external electrical muscle stimulator to rehabilitate the transferred muscle 2 weeks after surgery. The regimen was 3 times per day for 15 minutes to stimulate the muscle. We expect that using a muscle stimulator can reduce the atrophy of the transferred muscle during reinnervation of the nerve. However, further study will be needed to evaluate the effectiveness of rehabilitation therapy using an external muscle stimulator after free functional muscle transfer.

The main limitation of this study is its retrospective nature and relatively small number of patients. The relatively short followup period could be another limitation. An objective evaluation of the spontaneity of smiles was not performed in this study. In the future, functional magnetic resonance imaging, electromyography, and nerve conduction tests should be used to investigate cortical adaptation and the spontaneity of smiles.

\section{NOTES}

\section{Conflict of interest}

No potential conflict of interest relevant to this article was reported.

\section{Ethical approval}

The study was approved by the Institutional Review Board of Asan Medical Center (IRB No. 2018-1272) and performed in accordance with the principles of the Declaration of Helsinki. Written informed consents were obtained.

\section{Patient consent}

The patients provided written informed consent for the publication and the use of their images.

\section{Author contribution}

Study concept and design: Oh TS. Data analysis and interpretation, drafting of the manuscript: Kim HB. Critical revision of the manuscript for important intellectual content: Choi JW. Technical, surgical support: Jeong WS.

\section{ORCID}

Tae Suk Oh https://orcid.org/0000-0001-8174-8915

Hyung Bae Kim https://orcid.org/0000-0002-0096-7401

Jong Woo Choi https://orcid.org/0000-0001-8047-9821

Woo Shik Jeong https://orcid.org/0000-0002-5923-0383

\section{REFERENCES}

1. Gousheh J, Arasteh E. Treatment of facial paralysis: dynamic reanimation of spontaneous facial expression-apropos of 655 patients. Plast Reconstr Surg 2011;128:693e-703e.

2. Terzis JK, Noah ME. Analysis of 100 cases of free-muscle transplantation for facial paralysis. Plast Reconstr Surg 1997; 99:1905-21.

3. Faria JC, Scopel GP, Busnardo FF, et al. Nerve sources for facial reanimation with muscle transplant in patients with unilateral facial palsy: clinical analysis of 3 techniques. Ann Plast Surg 2007;59:87-91.

4. Klebuc MJ. Facial reanimation using the masseter-to-facial nerve transfer. Plast Reconstr Surg 2011;127:1909-15.

5. Coombs CJ, Ek EW, Wu T, et al. Masseteric-facial nerve coaptation: an alternative technique for facial nerve reinnervation. J Plast Reconstr Aesthet Surg 2009;62:1580-8.

6. Collar RM, Byrne PJ, Boahene KD. The subzygomatic triangle: rapid, minimally invasive identification of the masseteric nerve for facial reanimation. Plast Reconstr Surg 2013; 132:183-8.

7. Chuang DC, Lu JC, Anesti K. One-stage procedure using spinal accessory nerve (XI)-innervated free muscle for facial paralysis reconstruction. Plast Reconstr Surg 2013;132: $117 \mathrm{e}-129 \mathrm{e}$.

8. Biglioli F, Colombo V, Tarabbia F, et al. Double innervation in free-flap surgery for long-standing facial paralysis. J Plast Reconstr Aesthet Surg 2012;65:1343-9.

9. Bae YC, Zuker RM, Manktelow RT, et al. A comparison of commissure excursion following gracilis muscle transplantation for facial paralysis using a cross-face nerve graft versus the motor nerve to the masseter nerve. Plast Reconstr Surg 2006;117:2407-13.

10. Cardenas-Mejia A, Covarrubias-Ramirez JV, Bello-Margolis $A$, et al. Double innervated free functional muscle transfer for facial reanimation.J Plast Surg Hand Surg 2015;49:183-8. 
11. Manktelow RT, Tomat LR, Zuker RM, et al. Smile reconstruction in adults with free muscle transfer innervated by the masseter motor nerve: effectiveness and cerebral adaptation. Plast Reconstr Surg 2006;118:885-99.
12. Lifchez SD, Matloub HS, Gosain AK. Cortical adaptation to restoration of smiling after free muscle transfer innervated by the nerve to the masseter. Plast Reconstr Surg 2005; 115 : 1472-9. 